\title{
Atividade "in vitro" de extratos de Pycnoporus sanguineus e Lentinus crinitus sobre o fitopatógeno Fusarium sp
}

\author{
Ádrya FIGUEIREDO ${ }^{1 *}$, Ademir CASTRO E SILVA ${ }^{1}$ \\ ${ }^{1}$ Centro de Estudos Superiores de Parintins - CESP/UEA, Programa de Pós-graduação em Biotecnologia e Recursos Naturais da Amazônia-MBT. Estrada Odovaldo Novo, s/n, \\ Estrada do Aeroporto. Parintins, Amazonas, Brasil. adryafigueiredo@yahoo.com.br, acesilva@uea.edu.br \\ * Autor Correspondente: adryafigueiredo@yahoo.com.br
}

\section{RESUMO}

O controle alternativo de doenças de plantas tem como objetivo minimizar o impacto ambiental através da utilização de produtos naturais. Assim, este trabalho teve como objetivo avaliar a atividade in vitro de extrato aquoso e hidroalcoólico de Pycnoporus sanguineus e Lentinus crinitus contra Fusarium sp., conhecido por causar doenças das culturas. Os fungos foram coletados em áreas urbanas e rurais de Parintins-AM, e testados em diferentes concentraçóes de extratos, sendo avaliadas a inibição de crescimento micelial, a inibição da germinação de conídios e a inibição da germinação de esclerócios. Os melhores resultados de inibição do crescimento micelial foram obtidos com extratos hidroalcoólicos frios. Extratos de P. sanguineus obtidos em solvente hidroalcoólico frio e extrato aquoso ultrassônico e extrato de L. crinitus de solvente hidroalcoólico frio, inibiram mais de $92 \%$ da esporulação de conídios. Extratos aquosos quentes inibiram a germinação de escleródios, bem como o extrato de $P$. sanguineus hidroalcoólico frio. O consórcio dos fungos inibiram a germinação de escleródios em $1000 \mu \mathrm{g} \mathrm{mL}^{-1}$.

PALAVRAS-CHAVE: fungicida, controle alternativo, basidiomicetos

\section{Activity "in vitro" of extracts from Pycnoporus sanguineus and Lentinus crinitus on the pathogen Fusarium sp}

\section{ABSTRACT}

The alternative control of plant diseases aims to minimize environmental impacts through the use of natural products. The objective of this work was to evaluate the in vitro activity of aqueous and hydroalcoholic extracts from Pycnoporus sanguineus and Lentinus crinitus against Fusarium sp. A fungus known to cause disease in plants. Fungis amples were collected in the urban and rural areas of Parintins-AM, and tested against different extracts concentrations. Inhibition of mycelia growth, inhibition of conidial germination and inhibition of germination of sclerotia were assessed. Mycelial growth inhibition was highest with hydroalcoholic cold extracts. Hydroalcoholic and aqueous extracts from P. sanguineus obtained by ultrasonic ation and hydroalcoholic cold extract from L. crinitus caused $92 \%$ of conidia sporulation. Aqueous hot extracts inhibited sclerotia germination in both fungi samples as well as hydroalcoholic cold extract from L. crinitus. Fungi consortium inhibited sclerotia germination at $1000 \mu \mathrm{g} \mathrm{mL} \mathrm{mL}^{-1}$ concentration.

KEYWORDS: fungicides, alternative control, basidiomycetes 


\section{INTRODUÇÃO}

A maioria dos cultivos agrícolas esta sujeita a diversas doenças causadas por um conjunto amplo de fitopatógenos (Trigiano et al. 2 010). Um dos fitopatógenos amplamente distribuído ao redor do mundo, encontrado em todos os tipos de solo ou associados a inúmeras espécies vegetais, é o fungo Fusarium sp. Este fungo pode sobreviver por longos períodos de forma saprofítica sobre a matéria orgânica do solo e quando possível pode causar inúmeras doenças em diferentes espécies vegetais, sobretudo em culturas de importância econômica, causando grandes prejuízos (Martins 2005).

O gênero Fusarium é caracterizado pelo seu crescimento rápido, colônias com coloração pálida ou colorida (violeta à púrpura escuro ou do creme à laranja), com micélio aéreo e difuso (Martins 2005). A maioria das espécies de Fusarium é composta por fungos de solo com distribuição cosmopolita e ativo na decomposiçáo de substratos celulósicos das plantas, sendo que alguns isolados são parasitas das plantas. A patogenicidade ao homem é rara, mas muitas espécies causam o apodrecimento de estoques e são importantes produtoras de toxinas (Leslie et al. 2001; Zemankova et al. 2001).

As características e patogenicidade do gênero Fusarium o torna de difícil controle para o produtor agrícola, fazendo com que a utilização de produtos químicos seja cada vez mais abusiva. Em virtude dos danos causados pelos fungicidas sintéticos, tanto ao homem quanto ao ambiente, a exigência do mercado por produtos agrícolas livres desses químicos torna-se cada vez maior. Nesse contexto, o controle biológico em produtos agrícolas restringe a aplicação abusiva de fungicidas, sendo um importante aliado ao meio ambiente e aos consumidores de tais produtos, uma vez que estes não possuem resíduos de defensivos agrícolas (Azevedo et al. 2006). Dentre os agentes fúngicos que podem atuar como biocontroladores de doenças de plantas, destaca-se àqueles da classe dos Basidiomicetos, que incluem aproximadamente 1.200 espécies identificadas (Vanderlinde 2010).

As propriedades terapêuticas dos Basidiomycetes vêm sendo reconhecidas por milênios pelos povos orientais, sendo que os primeiros livros chineses sobre produtos naturais, medicinais, datam de 200 anos atrás (Vanderlinde 2010). Por isso, muitos estudos científicos foram conduzidos com basidiomas destes fungos, com a finalidade de isolar e identificar quimicamente as diversas substâncias ativas, e também determinar suas potencialidades terapêuticas (Lomascolo et al. 2003). Assim, o presente trabalho teve por finalidade avaliar a potencialidade in vitro dos extratos de basidiomicetos de P. sanguineus e L. crinitus em inibir o fitopatógeno Fusarium sp., isolado de culturas de alface do município de Parintins-AM.

\section{MATERIAL E MÉTODOS}

Carpóforos de Pycnoporus sanguineus e Lentinus crinitus foram coletados em áreas rurais e periurbana do município de Parintins, região do baixo Amazonas, sendo triturados e utilizados na obtenção dos extratos aquoso frio $\left(\mathrm{H}_{2} \mathrm{O}-\mathrm{F}\right)$, quente $\left(\mathrm{H}_{2} \mathrm{O}-\mathrm{Q}\right)$, ultrassônico $\left(\mathrm{H}_{2} \mathrm{O}-\mathrm{US}\right)$, hidroalcóolicos a frio (H-F) e quente (H-Q) na proporção de 1:1 (água:etanol). Utilizou-se extraçóes por meio de extrator Soxhlet, em extração média de 8 horas, em temperatura de $40^{\circ} \mathrm{C}$; extração ultrassônica em ultrassom de frequência $40 \mathrm{kHz}$ e potencia de $30 \mathrm{~W}$, à temperatura de $50{ }^{\circ} \mathrm{C}$ por 25 min de extraçáo e a frio por $72 \mathrm{~h}$ em recipiente âmbar. O consórcio dos fungos foi preparado com carpóforo triturado de $P$. sanguineus e de $L$. crinitus na proporçáo de $1: 1 \mathrm{em} 250 \mathrm{ml}$ de soluçáo hidroalcóolica (1:1). Os extratos obtidos foram concentrados em evaporador rotativo à pressáo reduzida, observando-se o ponto de ebulição de cada solvente (etanol a $78,5^{\circ} \mathrm{C}$ água a $\left.100^{\circ} \mathrm{C}\right)$.

Para o isolamento do fitopatógeno, Fusarium sp, fragmentos de 8 a $12 \mathrm{~cm}$, de amostras vegetais de hortaliças foram pesadas e após realizar assepsia foram inoculadas, em fotoperíodo de $12 \mathrm{~h}$, em placa de Petri contendo meio de cultura BDA. Após o crescimento para a identificação do fitopatógeno, fragmentos das colônias fúngicas foram coradas em lactofenol azul algodáo e analisados em microscópio óptico para a observaçáo de estruturas reprodutivas, de resistência ou análise da morfologia das hifas (grampos de conexão, septação e etc.) (Hanline Menezes 1996). Os extratos fúngicos foram dissolvidos previamente em água destilada, e adicionados ao meio BDA nas concentraçôes de 1, 10, 100 e $1000 \mu \mathrm{gmL}^{-1}$, vertidos em placas de Petri, para realização dos testes: a) crescimento micelial; b) germinação de conídios e c) germinação de escleródios.

No teste do crescimento micelial discos de $5 \mathrm{~mm}$ de diâmetro, contendo micélio dos fungos foram transferidos para o centro das placas e incubados em BOD a $25^{\circ} \mathrm{C}$ em ausência de luz. A avaliaçáo foi realizada quando as parcelas testemunhas foram completamente tomadas pelos fungos, medindo-se o crescimento radial dos fungos submetidos aos tratamentos, em duas retas perpendiculares traçadas no fundo de cada placa.

Para o experimento de inibição da germinação de conídios foi utilizado o método do celofane descrito por Nelly et al (1978). Dez discos de papel celofane de 0,8 cm de diâmetro foram colocados em placas de Petri sobre discos de papel filtro embebidos com $5 \mathrm{~mL}$ da solução de cada extrato nas concentraçóes $1,10,100$ e $1000 \mu \mathrm{gmL}^{-1}$, em triplicata. Posteriormente, uma gota de suspensão de conídios do fitopatógeno, na concentração de $10^{4}$ conídios $\mathrm{mL}^{-1}$ foi depositada sobre cada disco de celofane. As placas assim 
preparadas foram mantidas em BOD sob fotoperíodo de $12 \mathrm{~h}$ e temperatura de $25^{\circ} \mathrm{C}$.

A observação foi feita em microscópio óptico após 16h de incubação, considerando-se como germinados, aqueles que apresentassem qualquer indício de formaçáo do tubo germinativo. A avaliaçáo foi feita somando-se os conídios germinados com os conídios não germinados (Nesp), obtendo-se assim um total de conídios (TC) por placa de Petri, calculando-se assim a percentagem de não germinação (Nesp*100/TC).

Já na avaliação da germinação de escleródios foram inoculados 10 escleródios em placas de Petri contendo meio de cultura BDA e cada um dos extratos, nas mesmas concentraçóes, preparadas de forma semelhante ao experimento de inibição do crescimento micelial descrito anteriormente. Incubadas por $72 \mathrm{~h}$ a $25^{\circ} \mathrm{C}$ em fotoperíodo de $12 \mathrm{~h}$. A avaliação foi feita medindo-se o crescimento radial dos fungos submetidos aos tratamentos, em duas retas perpendiculares traçadas no fundo de cada placa.

Enfim, para a análise estatística dos dados utilizou-se o BioEstat 5.0, onde se obteve os parâmetros descritivos (média, desvio padrão, variância) dos dados, teste de correlação entre as variáveis, teste ANOVA para verificar diferenças entre os tratamentos e de Tukey $(\mathrm{p}<0,05)$ para contrastes das médias.

\section{RESULTADOS}

\section{Crescimento micelial}

Em comparação ao tratamento com a testemunha, houve efeito significativo, com o menor crescimento micelial os extratos $\mathrm{H}-\mathrm{F}$ (Tabela 1). No extrato $\mathrm{H}_{2} \mathrm{O}-\mathrm{Q}$ de $P$. sanguineus, foi onde ocorreu o menor crescimento micelial do Fusarium sp, crescimento $60 \%$ menor, nas concentraçóes 1,100 e $1000 \mu \mathrm{gmL}^{-1}$, e $40 \%$ na concentração de $10 \mu \mathrm{gmL}^{-1}$, em comparação com a testemunha. Já o extrato do basidiocarpo de $L$. crinitus obteve o melhor resultado em $10 \mu \mathrm{gmL}^{-1} \mathrm{com}$ $50 \%$ a menos do crescimento. O extrato do consórcio dos fungos não revelou dados significativos em comparação aos experimentos testemunha.

$\mathrm{O}$ extrato $\mathrm{H}_{2} \mathrm{O}-\mathrm{F}$ de $P$. sanguineus proporcionou os menores valores de crescimento em relação ao $L$. crinitus e consórcio desses fungos, com crescimento micelial $70 \%$ menor nas concentrações 10 e $1000 \mu \mathrm{gmL}^{-1}$ em relação à testemunha. Nos tratamentos com extrato de L. crinitus e consórcio, não houve inibiçáo na concentração de $1 \mu \mathrm{g} \mathrm{mL} \mathrm{m}^{-1}$, e nas demais concentraçôes variaram de 10 a $40 \%$.

$\mathrm{Na}$ maioria dos tratamentos realizados em extratos H-Q, não houve inibição no crescimento micelial, em relação à testemunha. No extrato L. crinitus, o crescimento do Fusarium sp. em todas as concentraçóes foi maior quando comparado com a testemunha. Já para o extrato de $P$. sanguineus nas concentraçóes de 1 e $10 \mu \mathrm{gmL}^{-1}$, o crescimento foi $80 \%$ maior do que da testemunha. Por outro lado, o extrato do consórcio desses fungos mostrou resultados equiparados com aqueles das testemunhas.

$\mathrm{O}$ extrato $\mathrm{H}-\mathrm{F}$ dos fungos estudados, inibiu o crescimento do Fusarium sp em até $70 \%$ na maior concentração, $50 \%$ e $60 \%$ nas concentraçôes de 10 e $100 \mu \mathrm{gmL}^{-1}$, respectivamente. Já o extrato em consórcio não tiveram bons resultados, variando de 10 a $50 \%$ de inibição. O extrato aquoso ultrassônico dos fungos, inibiu o crescimento em $70 \%$ na maior concentração testada em relação à testemunha, e de 40 e $60 \%$, nas concentraçôes 10 e $1000 \mu^{\prime g m L}{ }^{-1}$, respectivamente (Tabela 1).

\section{Germinação dos conídios}

Os melhores resultados, com mais de $92 \%$ dos conídios não germinados, obteve-se com os extratos de P. sanguineus em solvente $\mathrm{H}_{2} \mathrm{O}-\mathrm{US}$ e $\mathrm{H}-\mathrm{F}$, assim como os extratos de L. crinitus revelou seu melhor resultado em solvente H-F. Já para o extrato do Consórcio dos fungos o $\mathrm{H}_{2} \mathrm{O}$-US foi onde ocorreu o maior percentual de conídios não germinados.

A análise de dados dos extratos de basidiocarpos de $P$. sanguineus nas concentraçóes e solventes testados mostrou que o extrato $\mathrm{H}_{2} \mathrm{O}-\mathrm{US}$ nas concentraçôes de 10 e $100 \mu \mathrm{gmL}-$ ${ }^{1}$ e extrato H-F na concentração de $100 \mu g \mathrm{~mL}^{-1}$ tiveram os melhores resultados, inibindo a germinação dos conídios em mais de $92 \%$. Já na concentração de 1 e $1000 \mu \mathrm{gmL}$ ${ }^{1}$ apresentou inibição de $34,1 \%$ e 79,8\% nos solventes de extração $\mathrm{H}_{2} \mathrm{O}-\mathrm{US}$ e H-F, respectivamente (Figura 1).

A inibição da germinação dos conídios frente aos extratos de $L$. crinitus mostrou que o solvente H-F na concentraçáo de $10 \mathrm{\mu gmL}^{-1}$ inibiu 95,4\%, sendo este o melhor resultado, pois nessa mesma concentração nos diferentes solventes de extração variou entre 26 a $33 \%$. Em $1 \mu \mathrm{gmL}^{-1}$ os resultados significativos são dos extratos aquosos (quente e frio) e hidroalcóolico quente com 30 e 31\%. Enquanto que em 100 e $1000 \mathrm{\mu gmL}^{-1}$ os extratos aquoso a quente e hidroalcóolico a quente mostraram 49 e $65 \%$, respectivamente (Figura 2).

A inibição da germinação de conídios acima de 90\%, indica que os extratos do carpóforo dos fungos $P$. sanguineus e L. crinitus tem potencial inibição de conídios do Fusarium sp., fato que pode estar associado a liberação de compostos antimicrobiano por estes basidiomicetos. O consórcio dos fungos $P$. sanguineus e $L$. crinitus nos diferentes solventes de extração mostrou que o extrato $\mathrm{H}_{2} \mathrm{O}-\mathrm{US}$ foi o que apresentou inibição na germinaçấo de conídios de $97 \%$, 89\% e 94\% nas concentraçôes 10,100 e $1000 \mu g m L^{-1}$, respectivamente. Enquanto o melhor resultado na concentração de $1 \mu \mathrm{gmL}^{-1}$ foi o extrato $\mathrm{H}_{2} \mathrm{O}-\mathrm{F}$ com $47 \%$ de inibição (Figura 3).

$\mathrm{Na}$ tentativa de verificar o grau de relação entre as variáveis de concentração e a percentagem de conídios não germinados, 
Tabela 1 - Percentual do crescimento micelial (cm) de Fusariumsp., contendo meio de cultura BDA + extratos de basidiomicetos nas concentrações de 1 à $1000 \mu \mathrm{gmL}^{-1}$

\begin{tabular}{|c|c|c|c|c|c|}
\hline \multirow{2}{*}{ Extrato } & \multirow{2}{*}{ Fungo } & \multicolumn{4}{|c|}{ Tratamentos } \\
\hline & & $1 \mu \mathrm{gmL}^{-1}$ & $10 \mu \mathrm{gmL}^{-1}$ & $100 \mu \mathrm{gmL}^{-1}$ & $1000 \mu \mathrm{gmL}^{-1}$ \\
\hline \multirow{3}{*}{$\mathrm{H}_{2} \mathrm{O}-\mathrm{Q}$} & P. sanguineus & 40 & 60 & 40 & 40 \\
\hline & L. crinitus & 80 & 50 & 60 & 60 \\
\hline & Consórcio & 100 & 100 & 90 & 80 \\
\hline \multirow{3}{*}{$\mathrm{H}_{2} \mathrm{O}-\mathrm{F}$} & P. sanguineus & 40 & 30 & 60 & 30 \\
\hline & L. crinitus & 90 & 60 & 70 & 60 \\
\hline & Consórcio & 90 & 80 & 80 & 80 \\
\hline \multirow{3}{*}{$\mathrm{H}_{2} \mathrm{O}-\mathrm{US}$} & $P$. sanguineus & $70^{a}$ & $50^{a}$ & $50^{a}$ & $30^{\mathrm{a}}$ \\
\hline & L. crinitus & $70^{a}$ & $60^{a}$ & $40^{\mathrm{a}}$ & $30^{\mathrm{a}}$ \\
\hline & Consórcio & $80^{b}$ & $50^{\mathrm{a}}$ & $40^{\mathrm{a}}$ & $30^{c}$ \\
\hline \multirow{3}{*}{$H-Q$} & P. sanguineus & $130^{\mathrm{a}}$ & $180^{\mathrm{b}}$ & $70^{c}$ & $80^{\mathrm{a}}$ \\
\hline & L. crinitus & $130^{\mathrm{a}}$ & $170^{\mathrm{a}}$ & $170^{\mathrm{a}}$ & $140^{\mathrm{a}}$ \\
\hline & Consórcio & $110^{\mathrm{a}}$ & $80^{a}$ & $80^{\mathrm{a}}$ & $90^{\mathrm{a}}$ \\
\hline \multirow{4}{*}{$\mathrm{H}-\mathrm{F}$} & P. sanguineus & 50 & 50 & 40 & 30 \\
\hline & L. crinitus & 70 & 50 & 40 & 30 \\
\hline & Consórcio & 100 & 50 & 70 & 80 \\
\hline & Testemunha & 100 & 100 & 100 & 100 \\
\hline
\end{tabular}

Letras iguais na horizontal significa que não há diferença estatística ao nível de 95\% de probabilidade.

quatro modelos estatísticos (linear, geométrica, exponencial e logarítmico) foram testados. Os maiores índices de determinação $\left(R^{2}\right)$ foram obtidos para o consórcio de fungos, embora para o $\mathrm{H}_{2} \mathrm{O}-\mathrm{US}$ este índice sido fraco.De modo geral, o melhor modelo para se determinar o percentual de conídios não germinados em função da concentraçáo, para $P$. sanguineus foi o logarítmico $\left(\mathrm{R}^{2}=0,97\right)$ do extrato $\mathrm{H}-\mathrm{Q}$, para $L$. crinitus o logarítmico $\left(\mathrm{R}^{2}=0,91\right)$ do extrato $\mathrm{H}_{2} \mathrm{O}-\mathrm{Q}$ e para o consórcio o geométrico $\left(\mathrm{R}^{2}=0,98\right)$ do extrato $\mathrm{H}_{2} \mathrm{O}-\mathrm{F}$.

\section{Germinação dos escleródios}

Os extratos aquosos obtidos pelo método à quente $\left(\mathrm{H}_{2} \mathrm{O}-\mathrm{Q}\right)$ e o hidroalcóolico à frio (H-F) de P. sanguineus, inibiram a germinação em todas as concentraçóes testadas. Comportamento similar ocorreu para o extrato $\mathrm{H}_{2} \mathrm{O}-\mathrm{Q}$ em $L$. crinitus onde não houve germinação dos escleródios (Tabela 2). Para os extratos $\mathrm{H}_{2} \mathrm{O}-\mathrm{US}$ e H-Q de L. crinitus na concentração de 1 e $10 \mu \mathrm{gmL}^{-1}$, também náo ocorreu germinação dos escleródios. O percentual máximo de germinação nos extratos de P. sanguineus foi de $25 \%$ e nos extratos de $L$. crinitus foi de $38 \%$, em relação a testemunha. Os extratos aquosos $\left(\mathrm{H}_{2} \mathrm{O}-\mathrm{Q}\right.$, $\mathrm{H}_{2} \mathrm{O}-\mathrm{F}$ ) e o hidroalcóolico (H-F) do consórcio inibiram totalmente a germinação dos escleródios na concentraçáo de $1000 \mathrm{\mu gmL}^{-1}$. Por outro lado, o extrato aquoso ultrassônico $\left(\mathrm{H}_{2} \mathrm{O}-\mathrm{US}\right)$ inibiu a germinação em concentraçóes mais baixa (1 e $10 \mu \mathrm{gmL}^{-1}$ ). Observa-se também que no extrato H-Q, em comparaçáo com os outros tratamento, foi onde ocorreu o maior percentual de escleródios germinados (Tabela 2).
Quando testou-se os extratos aquoso quente e frio, e o hidroalcóolico frio do consórcio de fungos (Psanguineus + L.crinitus), na maior concentração, não houve germinação dos escleródios. Ressalta-se, entretanto, que os extratos produzidos com o consorcio dos fungos em outras concentraçóes apresentaram resultados inferiores em relaçáo aos extratos preparados com os basidiomicetos isoladamente.

\section{DISCUSSÃO}

Observa-se que os isolados de P. sanguineus apresentaram maior efeito inibitório sobre a não germinaçáo de conídios e germinaçáo de escleródios. Uma das hipóteses para explicar tal fato é que alguns isolados podem apresentar maior concentraçáo de substâncias inibitórias ou diferir na composição dessas substâncias conforme sugerido por Tunucci (2004). Em extratos hidroalcóolicos frio (H-F) de L. crinitus a inibição de conídios mostrou-se melhor em concentraçôes menores $\left(10 \mu \mathrm{g} \mathrm{mL}^{-1}\right)$. Com o aumento da concentração provavelmente ocorreu uma sinergia dos compostos, o que levou diminuição do efeito dos extratos.

A ação dos extratos testados parece estar associada ao tipo de extração utilizada. Ressalta-se, que a produção de extratos brutos provenientes dos carpóforos dos fungos $P$. sanguineus e L.crinitus é um processo que envolve a transferência de massa de um soluto de uma matriz sólida para um solvente (Cardozo-Filho et al. 1997). Este tipo de extração é utilizada na recuperação de compostos de interesse, e no caso do uso da água com solvente de elevada polaridade, utilizado para 

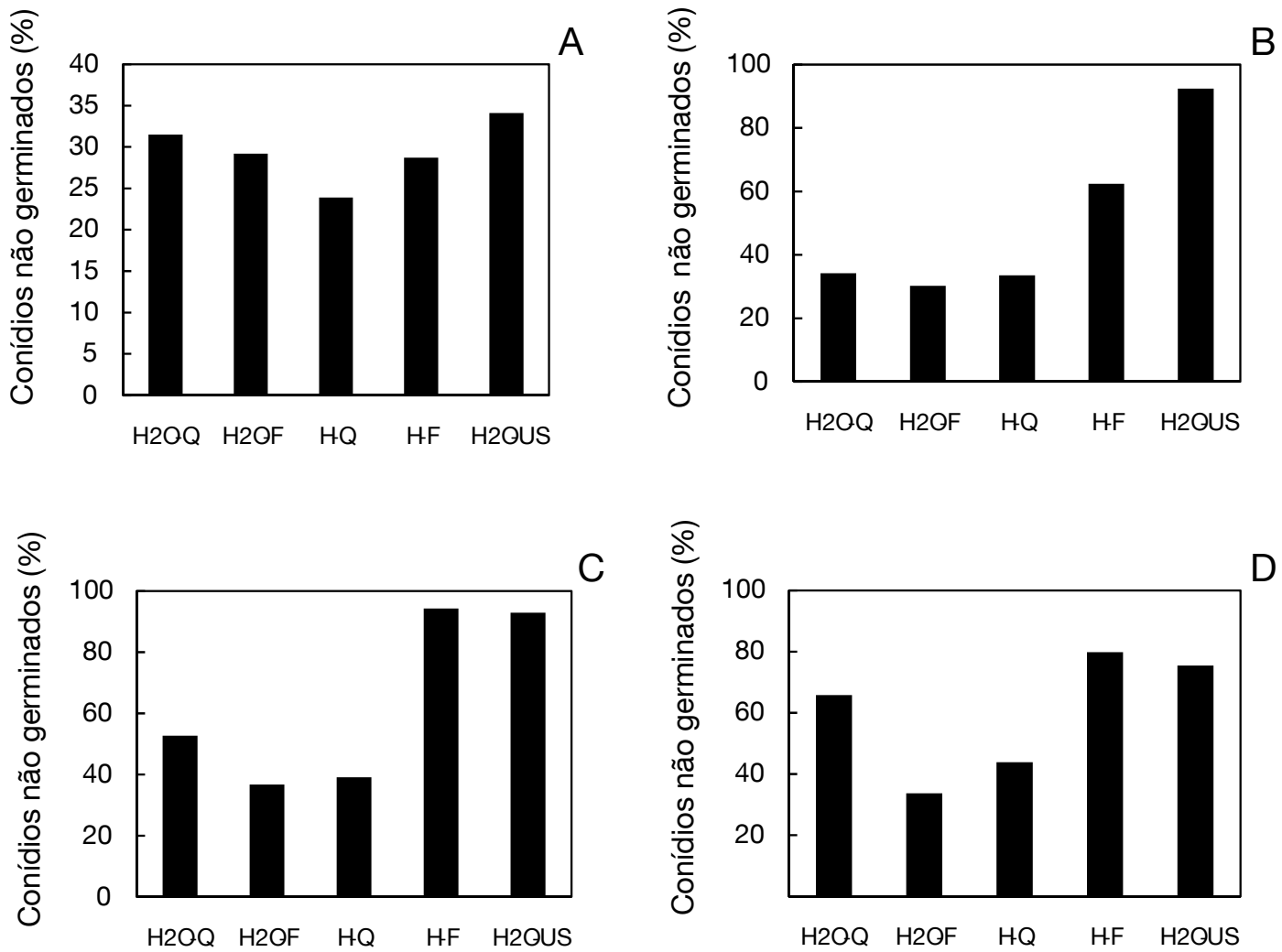

Figura 1 - Percentual de conídios não germinados na concentração de (A) $1 \mu \mathrm{g} \mathrm{mL}^{-1}$, (B) $10 \mu \mathrm{g} \mathrm{mL}^{-1}$, (C) $100 \mu \mathrm{g} \mathrm{mL}^{-1} \mathrm{e}$ (D) $1000 \mu \mathrm{g} \mathrm{mL}-1$,em extratos de $P$. sanguineus em diferentes solventes de extração. (Legenda: $\mathrm{H}_{2} \mathrm{O}-\mathrm{Q}$ extrato aquoso quente; $\mathrm{H}_{2} \mathrm{~F}-\mathrm{Q}$ extrato aquoso frio; $\mathrm{H}-\mathrm{Q}$ extrato hidroalcóolico quente; $\mathrm{H}-\mathrm{F}$ extrato hidroalcóolico frio e $\mathrm{H}_{2} \mathrm{O}$-US extrato aquoso ultrassônico)

extração de compostos hidrofílicos. Sáo esses compostos que podem estar atuando no metabolismo fúngico para inibir a germinação de escleródios de Fusarium sp à baixa concentração proporcionado pelo extrato aquoso dos fungos testados. Piccinin (2000), por exemplo, mostrou o efeito inibitório na germinação de Ezseroliilum turacum e no desenvolvimento micelial de Colletrochium sublinealum do extrato aquoso do basidiocarpo de Lentinula edodes em concentraçôes superiores àquelas testadas na presente pesquisa.

Interessantemente para o extrato aquoso a quente de P.sangunieus e L. crinitus ocorreu a inibição total da germinação dos escleródios de Fusarium em todas as concentraçóes testadas. Jones e Kinghorn (2006) comentam que o calor necessário para realizar esse tipo de extração pode levar à decomposição de compostos termos sensíveis. Para nossos resultados, portanto, podemos inferir que a decomposição de compostos termo sensíveis, estes não teriam nenhuma influência no metabolismo do Fusarium para inibir a germinação dos escleródios. Neste caso, os extratos dos diferentes fungos ou teriam compostos similares que poderiam atuar na inibição ou a ação sinergética de compostos contribuíram para esse comportamento. Ressalta-se, por outro lado, a potencialidade do extrato aquoso do basidiocarpo de P. sanguineus na inibição da germinação de esporos de C. lindemuthianum (Baldo 2008).

Calixto (2001) comenta que a extração hidroalcoolica a frio, possibilita uma extração de distintas categorias de princípios ativos, incluindo substâncias de diferentes graus de polaridade. Nosso resultado mostrou que nesse tipo de extração, o "extrato bruto total" do fungo P. sanguineus inibiu a germinação dos escleródios de Fusarium sp em todas as concentrações testadas. Resultado contrário foi obtido para o extrato do basidicarpo de L. crinitus onde para esse tipo de extração não ocorreu à inibição total para quaisquer das concentraçóes testadas. Apesar dos extratos terem sido obtidos pelo mesmo tipo de extração, possivelmente há uma quantidade e variedade de compostos presentes que proporcionam esse comportamento diferenciado entre os extratos fungicos, conforme descrito por Oliveira et al. (2008).

Os resultados mostram que nas condições de extração, o extrato obtido apresenta maiores teores de compostos com atividade de inibição da germinação de escleródios e germinação de conídios de Fusarium sp, que podem ser compostos fenólicos, já citado por Tane Zou. (2001), Strobelet 

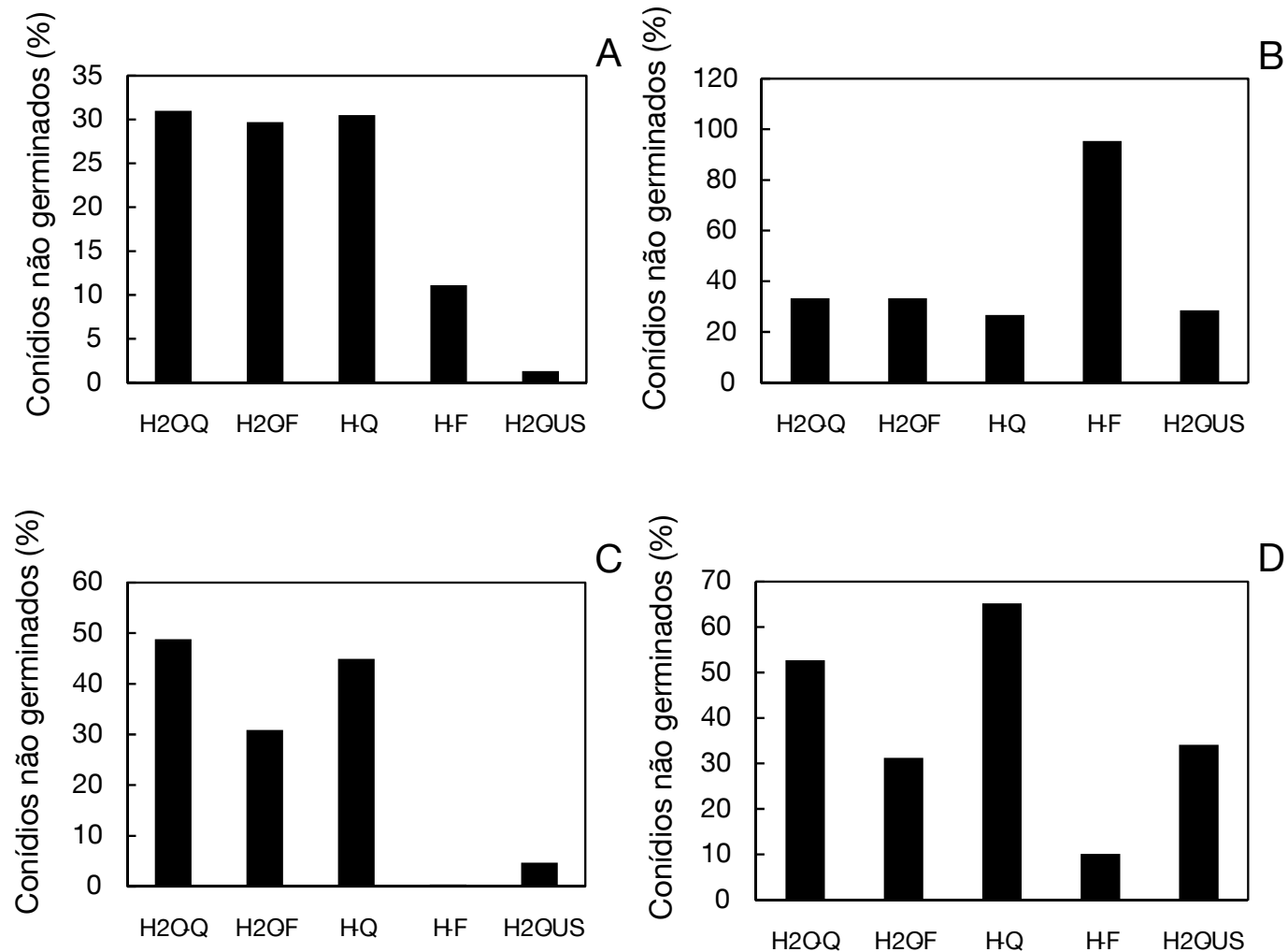

Figura 2 - Percentual de conídios não germinado na concentração de (A) $1 \mu \mathrm{g} \mathrm{mL}^{-1}$, (B) $10 \mu \mathrm{g} \mathrm{mL}^{-1}$, (C) $100 \mu \mathrm{g} \mathrm{mL}^{-1} \mathrm{e}$ (D) $1000 \mu \mathrm{g} \mathrm{mL} \mathrm{L}^{-1}$, em extratos de $L$. crinitus em diferentes solventes de extração. (Legenda: $\mathrm{H}_{2} \mathrm{O}-\mathrm{Q}$ extrato aquoso quente; $\mathrm{H}_{2} \mathrm{~F}-\mathrm{Q}$ extrato aquoso frio; $\mathrm{H}-\mathrm{Q}$ extrato hidroalcóolico quente; $\mathrm{H}-\mathrm{F}$ extrato hidroalcóolico frio e $\mathrm{H}_{2} \mathrm{O}$-US extrato aquoso ultrassônico).

al. (2004) e Valeriano et al.(2007), e que encontram-se ligados a outros compostos e são extraídos no $\mathrm{pH}$ alcalino como ocorreu nas nossas extraçóes.

Quanto à inibição da germinação dos conídios nos extratos aquosos de $P$. sanguineus, o método ultrassônico apresentou o melhor resultado em todas as concentraçóes testadas. Segundo Luz (1998) o processo ultrassônico apresenta menor percentual de perda por retenção irreversível, significando que extrai compostos menos complexos e de menor peso molecular, provavelmente devido ao fato das ondas

Tabela 2 - Percentual de germinação dos escleródios, em relação à testemunha, de Fusarium sp, contendo meio de cultura BDA + extratos nas concentrações de 1 à $1000 \mu \mathrm{gmL}^{-1}$.

\begin{tabular}{|c|c|c|c|c|c|c|}
\hline Fungo & Concentração & $\mathrm{H}_{2} \mathrm{O}-\mathrm{Q}$ & $\mathrm{H}_{2} \mathrm{O}-\mathrm{F}$ & $\mathrm{H}_{2} \mathrm{O}-\mathrm{US}$ & $\mathrm{H}-\mathrm{Q}$ & $\mathrm{H}-\mathrm{F}$ \\
\hline \multirow{4}{*}{ P. sanguineus } & $1 \mu \mathrm{g} \mathrm{mL}^{-1}$ & 0 & 13 & 13 & 13 & 0 \\
\hline & $10 \mu \mathrm{g} \mathrm{mL}^{-1}$ & 0 & 13 & 13 & 0 & 0 \\
\hline & $100 \mu \mathrm{g} \mathrm{mL}^{-1}$ & 0 & 13 & 13 & 25 & 0 \\
\hline & $1000 \mu \mathrm{g} \mathrm{mL}^{-1}$ & 0 & 13 & 25 & 0 & 0 \\
\hline \multirow{4}{*}{ L. crinitus } & $1 \mu \mathrm{g} \mathrm{mL}^{-1}$ & 0 & 13 & 0 & 0 & 13 \\
\hline & $10 \mu \mathrm{g} \mathrm{mL}^{-1}$ & 0 & 13 & 0 & 0 & 38 \\
\hline & $100 \mu \mathrm{g} \mathrm{mL}^{-1}$ & 0 & 25 & 13 & 13 & 13 \\
\hline & $1000 \mu \mathrm{g} \mathrm{mL}^{-1}$ & 0 & 13 & 0 & 13 & 13 \\
\hline \multirow{4}{*}{ Consórcio } & $1 \mu \mathrm{g} \mathrm{mL}^{-1}$ & 25 & 25 & 0 & 25 & 25 \\
\hline & $10 \mu \mathrm{g} \mathrm{mL}^{-1}$ & 50 & 25 & 0 & 38 & 13 \\
\hline & $100 \mu \mathrm{g} \mathrm{mL}^{-1}$ & 13 & 13 & 50 & 75 & 13 \\
\hline & $1000 \mu \mathrm{g} \mathrm{mL}^{-1}$ & 0 & 0 & 50 & 75 & 0 \\
\hline Testemunha & & 100 & 100 & 100 & 100 & 100 \\
\hline
\end{tabular}



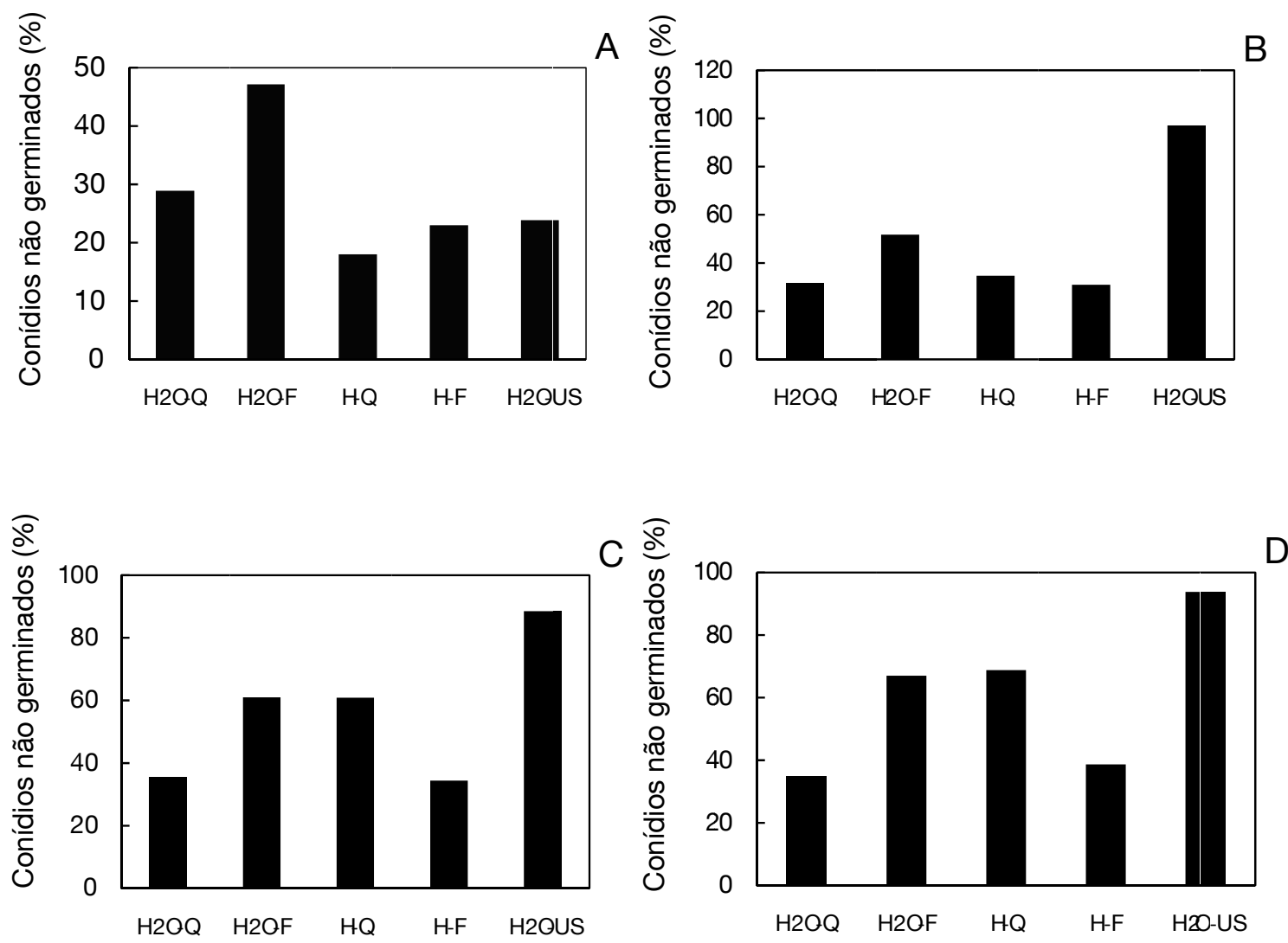

Figura 3 - Percentual de conídios não germinados na concentração de (A) $1 \mu \mathrm{g} \mathrm{mL}^{-1}$, (B) $10 \mu \mathrm{g} \mathrm{mL}^{-1}$, (C) $100 \mu \mathrm{gmL}^{-1}$ e (D) $1000 \mu \mathrm{gmL}^{-1}$,em extratos do consórcio de L. crinitus com $P$. sanguineus em diferentes solventes de extração. (Legenda: $\mathrm{H}_{2} \mathrm{O}-\mathrm{Q}$ extrato aquoso quente; $\mathrm{H}_{2} \mathrm{~F}-\mathrm{Q}$ extrato aquoso frio; $\mathrm{H}-\mathrm{Q}$ extrato hidroalcóolico quente; $\mathrm{H}-\mathrm{F}$ extrato hidroalcóolico frio e $\mathrm{H}_{2} \mathrm{O}$-US extrato aquoso ultrassônico).

ultrassônicas provocarem rompimento de ligaçóes fracas e a consequente redução no tamanho das moléculas extraídas.

A eficiência de extração usando técnica de ultra-som tem sido citada como igual ou melhor que a obtida com o extrator de Soxhlet (Escrivaet al. 1994). No presente estudo, a eficácia dos extratos obtidos com o emprego desse método não apresentou, de modo geral, resultados melhores do que àqueles obtidos com extração com Soxhlet.

Os mesmos resultados, referente à inibição da germinação dos conídios, também foram observados nos tratamentos com extrato aquoso ultrassônico do consórcio de $P$. sanguineus e L. crinitus, porém tais resultados provavelmente devem-se à presença do carpóforo de $P$. sanguineus, pois o mesmo teste realizado com isolado de $L$. crinitus náo resultou em bons resultados no extrato aquoso ultrassônico e sim no extrato aquoso quente.

\section{CONCLUSÃO}

Os extratos de P. sanguineus e L. crinitus mostraram efeito de inibição no crescimento micelial e na germinação de conídios e escleródios do fitopatógeno Fusarium sp, o que torna o presente resultado com potencial para desenvolvimento de tecnologia que utilize esses extratos como alternativa para o combate de fitopatógenos prejudiciais a lavoura.

\section{AGRADECIMENTOS}

Ao $\mathrm{CNPq}$ pela concessão da bolsa, apoio fundamental à execução deste trabalho. E a Universidade do Estado do Amazonas, por meio da Coordenação do Programa de Pós-graduação em Biotecnologia e Recursos Naturais da Amazônia-MBT, pela oportunidade e espaço concedido para a realização deste trabalho. 


\section{BIBLIOGRAFIA CITADA}

Azevedo, C. P.; Filho, A. C. C.; Hernz, G. P.; Reis, A. 2006. Recomendaçôes de manejo da antracnose do pimentão e das pimentas. Embrapa Hortaliças, Brasília 35:1-4.

Baldo, M.; Iurkiv, L.; Meinerz, C.C.; Franzener, G.; Kuhn, O. J.; Stangarlin, J. R. 2008. Controle de Colletotrichum lindemuthianumpor derivados de Pycnoporus sanguineus. Congresso Paulista de Fitopatologia, Campinas. Summa Phytopathologica, 34:94.

Calixto, J.B. 2001. Plantas medicinais sob a ótica da quimica medicinal moderna. Santa Catarina: Ed Argos, 2001,78-91p.

Cardozo-Filho, L; Ferrua, F. Q; Meireles, M. A. A. 1997. Estudo do processo da extraçáo supercrítica de óleos essenciais de produtos naturais. Ciência e Tecnologia dos Alimentos 17:449-455.

Escriva, C.; Viana, E.; Molto, J. C.; Pico, Y.; Manes, J. J. 1994. Comparison of four methods for the determination of polycyclic aromatic hydrocarbons in airborne particulates. Journal of Chromatography A, 676:375-388.

Hanlin, R.T. e Menezes, M. 1996. Gêneros Ilustrados de actinomicetos. Universidade Rural de Pernambuco, Recife. 1996, 274p.

Jones, W. P.; Kinghorn, A. D. 2006.Extraction of plant secondary metabolites. In:Sarker, S. D.; Latif, Z.; Gray, A. I. (Ed.). Methods in biotechnology, v. 20, Natural Products Isolation, 2nd ed. Humana Press Inc., Totowa, 323-351p.

Leslie, J.F.; Zeller, K.A.; Summerell, B.A. 2001.Icebergs and species in populations of Fusarium. Physiological and Molecular Plant Pathology, 59:107-117.

Lomascolo, A; Record, E; Herpoel-Gimbert, I; Delattre, M; Robert, J. L; Georis, J; Dauvrin, T; Sigoilot, J. C e Asther, M. 2003. Overproduction of laccase by a monokaryotic strain of Pycnoporus cinnabarinususing ethanol as inducer. JournalAppliedMicrobiology.94:618-624.

Luz, L. P. da. 1998. Estudo do ultra-som como técnica de extração de carvóes e caracterização dos hidrocarbonetos poliaromáticos. Dissertação de Mestrado, Pós-Graduação em Química da Universidade Federal do Rio Grande do Sul. 108p.

Martins, M. K. 2005. Variabilidade de Isolados de Fusarium spp. e estudo da interaçáo com a planta hospedeira. Tese de Doutorado, Universidade de São Paulo. Piracicaba, SP, 124p.
Nelly, D. 1978. Laboratory and greenhouse procedures methods for evaluation fungicides, nematicides and bactericides. Minessota: American Phytophathological Society. 140.

Oliveira, M. S.; Badiale-Furlong, E. 2008. Screening of antifungal and antimycotoxigenic activity of plant phenolic extracts. World Mycotoxin Journal, 1: 2: 1-10.

Piccinin, E. 2000. Potencial de preparaçöes do cogumelo comestivel "shiitake" (Lentinula edodes) no controle de fitopatógenos fúngicos, bacterianos e virais em sorgo, maracujá e fumo. Tese de Doutorado, Escola Superior de Agricultura "Luis de Queiroz". Piracicaba, $160 \mathrm{p}$.

$(3,12)$ Many of these compounds are bioactive, and the range includes alkaloids, steroids, terpenoids, peptides, polyketones, flavonoids, quinols and phenols as well as some chlorinated compounds.Strobel, G. A, Daisy, B., Castillo, U. e Harper, J. 2004 Natural products from endophytic microorganisms. J. Nat. Journal Natural Product, 67:257-268.

Tan, R.X. e Zou, W.X. 2001. Endophytes: a rich source of functional metabolites. Natural Product Reports, 18:448-459.

Trigiano, R. N; Windham, M. T e Windham, A. S. 2010. Fitopatologia: conceitos e exercícios de laboratório. 2 ed. Porto Alegre: Artmed, 2010, 576p.

Tonucci, N. M. 2004. Efeito de extratos aquosos de basidiocarpo e micélio de Lentinula edodes (SHIITAKE) sobre Colletotrichum sublineolum, Alternaria solani, Xanthomonas axonopodispv. passiflorae e Tobaccomosaic vírus (TMV). Dissertaçáo de Mestrado. Escola Superior de Agricultura "Luiz de Queiroz". Universidade de São Paulo. 102p.

Valeriano, V. S; Silva, A. M. F; Santiago M. F; Garcia, T. A. 2007. Estudos de Indutores para a Produção de Lacase por Picnoporus sanguineus. Revista Eletrônica de Farmácia, 4:112-116.

Vanderlinde, D. G. 2010. Atividade antimicrobiana de metabólitos produzidos pelo fungo Pycnoporus sanguineus (Linnaeus: Fries) MURRILL. Revista Saúde e Pesquisa, 3:11-16.

Zemankova, M. LEBEDA, A. 2001. Fusarium species, their taxonomy, variability and significance in plant pathology. Review. Plant Protection Science UZPI, 37: 25-42

Recebido em 23/06/2012

Aceito em 12/03/2013 